\title{
Ecological Partitioning and Invasive Ants (Hymenoptera: Formicidae) in a Tropical Rain Forest Ant Community from Fiji ${ }^{1}$
}

\author{
Darren Ward $^{2}$
}

\begin{abstract}
Determining composition and structure of ant communities may help understand how niche opportunities become available for invasive ant species and ultimately how communities are invaded. This study examined composition and structure of an ant community from a tropical rain forest in Fiji, specifically looking at spatial partitioning and presence of invasive ant species. A total of 27 species was collected, including five invasive species. Spatial partitioning between arboreal (foliage beating) and litter (quadrat) samples was evident with a relatively low species overlap and a different composition of ant genera. Composition and abundance of ants was also significantly different between litter and arboreal microhabitats at baits, but not at different bait types (oil, sugar, tuna). In terms of invasive ant species, there was no difference in number of invasive species between canopy and litter. However, the most common species, Paratrechina vaga, was significantly less abundant and less frequently collected in the canopy. In arboreal samples, invasive species were significantly smaller than endemic species, which may have provided an opportunity for invasive species to become established. However, taxonomic disharmony (missing elements in the fauna) could also play an important role in success of invasive ant species across the Pacific region. Invasive ants represent a serious threat to biodiversity in Fiji and on many other Pacific islands. A greater understanding of habitat susceptibility and mechanisms for invasion may help mitigate their impacts.
\end{abstract}

Explaining AND predicting the success of invasive species, the susceptibility of different habitats, and the role of the native community are major themes in biological invasions (Drake et al. 1989, Shea and Chesson 2002). Invasive ants are currently receiving considerable attention from around the globe, with increasing evidence of disruption to natural ant communities and ecosystems (Holway

${ }^{1}$ Financial support was provided by the University of Auckland, Landcare Research, and a Foundation for Research, Science and Technology doctoral scholarship. Manuscript accepted 17 October 2007.

${ }^{2}$ School of Biological Sciences, University of Auckland, Private Bag 92019, Auckland, New Zealand. Current address: Landcare Research, Private Bag 92170, Auckland, New Zealand (phone: +64-9-5744223; fax: +64-9-5744101; e-mail: wardda@landcareresearch.co $. n z)$.

Pacific Science (2008), vol. 62, no. 4:473-482

(C) 2008 by University of Hawai'i Press

All rights reserved
1999, Holway et al. 2002, O’Dowd et al. 2003, Sanders et al. 2003).

The composition and structure of ant communities are affected by multiple factors, which interact on different spatial and temporal scales. Abiotic factors, habitat requirements, and dispersal abilities strongly interact to shape ant communities (Andersen 1986, Savolainen and Vepsäläinen 1989). Andersen (1986) showed that patterns of ant community organization varied with habitat, and the strength of interspecific competition was dependent on habitat type. Several recent studies have also illustrated how habitat shapes ant communities (Yanoviak and Kaspari 2000, Gotelli and Ellison 2002). For example, there has been a major contrast between the canopy and the ground litter, and how these two habitat templates form distinct ant communities (Yanoviak and Kaspari 2000). Interspecific competition is also considered to be a major structuring force of ant communities, especially at local scales (Andersen 1992, Davidson 1998, Holway 1999, 
Albrecht and Gotelli 2001). Interspecific competition results in dominance hierarchies being formed through behavioral aggression, competitive exclusion at food resources, and distinctive foraging strategies for either accessing resources or avoiding dominant species (Savolainen and Vepsäläinen 1989, Andersen 1992, Davidson 1998, Holway 1999). The partitioning of resources, especially via space, diet, and time, also plays a large role in the coexistence of competing ant species (Schoener 1974, Albrecht and Gotelli 2001).

Invasive ant species also strongly affect the composition and structure of native ant communities (Holway 1999, Holway et al. 2002, Sanders et al. 2003). Invasive ant species may be particularly successful when the native ant fauna is disharmonious (taxonomically unbalanced). Such disharmonious communities are thought to be more susceptible to invasion because there are "missing elements" to the biota and thus many underutilized resources that invasive species can exploit (Drake et al. 1989, Shea and Chesson 2002). For example, Le Breton et al. (2005) recently examined the opportunity for invasion by the little fire ant, Wasmannia auropunctata (Roger), in New Caledonia, a disharmonious island ant community. They showed that food and nest site resources were not fully exploited by native ant communities. Wasmannia auropunctata also exploited the carbohydrate resources from native scale insects (Margarodidae) more effectively than native ants. As a result, the density of ants from invaded sites $(100 \%$ $W$. auropunctata) is now far greater than the natural densities of ants before invasion. In general, the Pacific island region is missing many ant genera from arboreal habitats that are common and diverse elsewhere (e.g., Crematogaster, Pseudomyrmex, Dolichoderus, Oecophylla, Polyrachis). Ants are also less abundant in arboreal habitats compared to elsewhere (for example, in New Caledonia native ants represent less than $5 \%$ of all canopy arthropods [Le Breton et al. 2005], and this is probably typical of other Pacific islands).

Invasive ants represent a serious threat to biodiversity across the Pacific island region, with a disproportionate number of invasive ant species already present (McGlynn 1999). However, much of the past research on invasive ants in the Pacific has been surveys and taxonomic checklists (Wetterer 2002, Wetterer and Vargo 2003, Wetterer 2006), with relatively few studies examining species coexistence, community structure, ecological partitioning, and susceptibility to invasion (but see Morrison 1996, Lester and Tavite 2004, Sarty et al. 2006). The study reported here examined the composition and structure of an ant community from a tropical rain forest in Fiji, specifically looking at the partitioning of ant species in arboreal and litter habitats and at food resources, and also at differences in susceptibility of arboreal and litter habitats to invasive ant species.

\section{MATERIALS AND METHODS}

\section{Study Site}

Fiji lies in the central Pacific Ocean between 12 and $21^{\circ} \mathrm{S}$ and between $175^{\circ} \mathrm{W}$ and $177^{\circ} \mathrm{E}$ longitudes (Evenhuis and Bickel 2005). Coloi-suva Forest Park $\left(18.05^{\circ} \mathrm{S}, 178.46^{\circ} \mathrm{E}\right.$, Fiji map series O28:695867) is a 245 ha park located approximately $11 \mathrm{~km}$ north of Suva city on the main island of Viti Levu (Figure 1). The park is $100-200 \mathrm{~m}$ above sea level and has an annual rainfall of $>4,100 \mathrm{~mm}$, of which the majority falls during the wet season of November to April (Evenhuis and Bickel 2005). The Colo-i-suva area has a humid tropical maritime climate, with mean daily temperatures from $19-23^{\circ} \mathrm{C}$ in July to $23-$ $29^{\circ} \mathrm{C}$ in January (Ash 1987). The park's flora is a mixture of native plant species, interplanted with South American mahogany (Swietenia macrophylla), an introduced tree used for timber production. The park was last logged in the 1950s. The locations in the park in which sampling took place are indicated in Figure 1 and are each approximately 1.5 ha in area.

\section{Arboreal Sampling}

The foliage of epiphytes, tree ferns, palms, and trees (hereafter referred to as trees) was sampled by beating. Foliage was brushed/ 


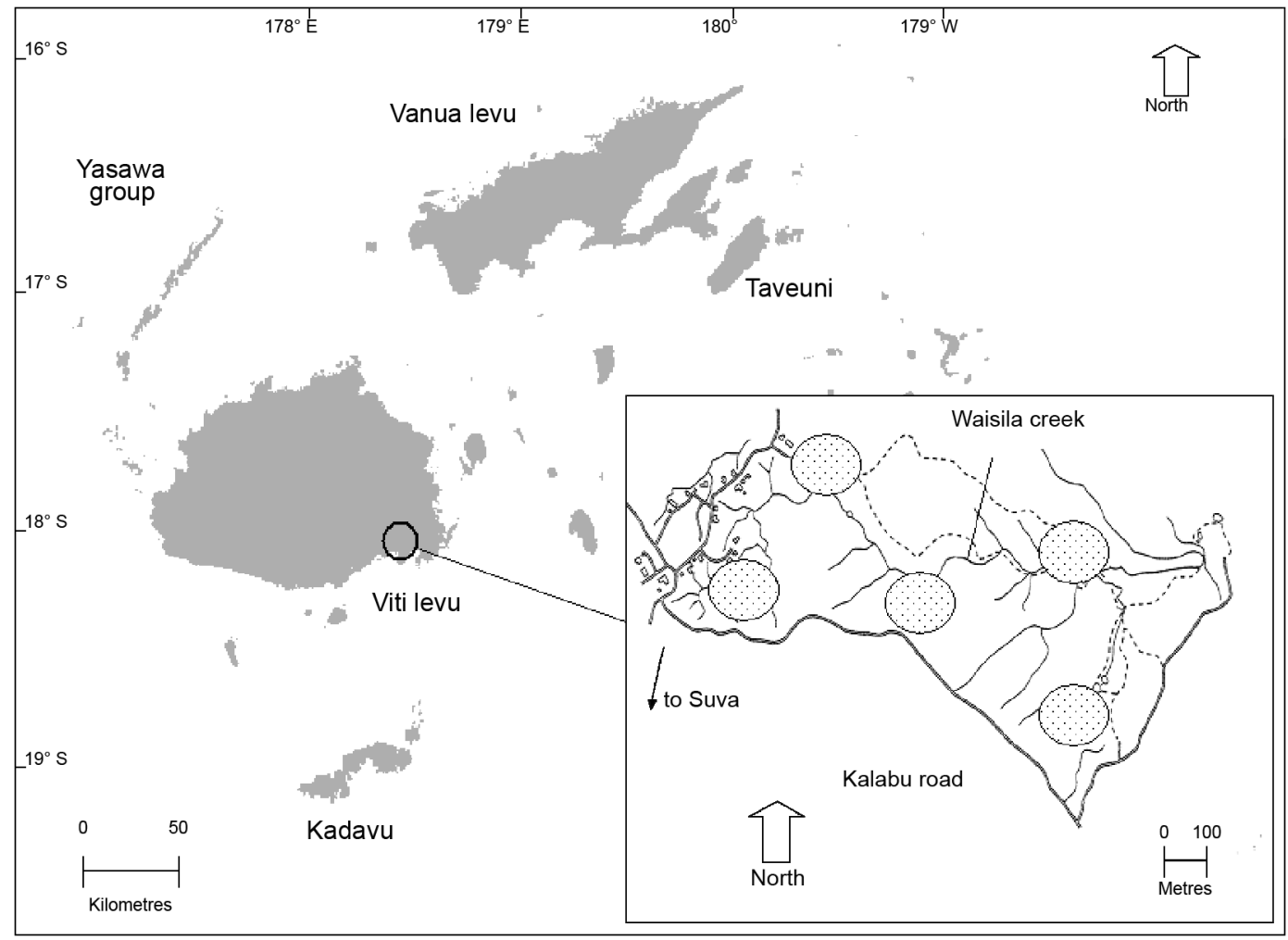

Figure 1. The main islands of Fiji and inset, Colo-i-suva Forest Park, with walking tracks (dotted lines), creeks (solid lines), and locations where sampling was undertaken (stippled circles).

tapped with a 2-m-long wooden stick five times to dislodge ants onto a white calico collecting sheet $(110$ by $75 \mathrm{~cm})$. Sampled foliage was approximately 2-4 $\mathrm{m}$ off the ground and is hereafter referred to as arboreal sampling. There are no identification guides to the native plant species in Fiji or Colo-i-suva Forest Park. Specimens of foliage were taken to park staff to obtain identification, and the publications of Smith (1979) and Watling (2005) were used for diagnostics and information. Arboreal samples were classified into five broad categories (number of samples): mahogany (Swietenia macrophylla), $n=21$; palms (Metroxylon vitiense, Pinanga coronata), $n=17$; tree ferns (Cyathea hornei), $n=30$; native tree species (mixture of Calophyllum vitiense, Palaquium spp., Endiandra spp., Canarium vitiense, and Garcinia cf. vitiensis), $n=52$; epiphytes (unidentified species), $n=21$. Epiphytes were sampled because several ant species from Fiji are known to inhabit them. Sampled trees were spaced at least $15 \mathrm{~m}$ apart, and the foliage of sampled trees did not interconnect or touch. Trees were haphazardly picked for sampling. Sampling took place on 3 days (24 September and 4-5 October 2005) between 0800 and 1600 hours. All ants were collected in fair to sunny weather and were collected from the beating sheet with an aspirator and immediately placed into a vial of $75 \%$ ethanol. Sampled trees were collected along the Kalabu Road area and the walking tracks beside Waisila Creek at least $5 \mathrm{~m}$ off established tracks (Figure 1).

\section{Litter Sampling}

To sample litter-dwelling ants a 0.5 by $0.5 \mathrm{~m}$ quadrat was placed on the ground, and litter 
within the quadrat was scooped into a white tray ( 30 by 40 by $10 \mathrm{~cm}$ ). Litter was sifted through a 1 by $1 \mathrm{~cm}$ wire mesh to exclude larger debris. Sticks and rotten wood within the quadrat were broken apart into the tray. Not all the litter from the quadrat could be placed into the tray at one time; between one and four trays were needed. However, a standardized time of $15 \mathrm{~min}$ was spent searching through the litter of each quadrat. Quadrats $(n=57)$ were spaced at least $15 \mathrm{~m}$ apart and were collected haphazardly along the Kalabu Road area and the walking tracks beside Waisila Creek (Figure 1). Sampling took place over 2 days (21-22 September 2005).

\section{Baiting Experiment}

Within the park, five transects $(150 \mathrm{~m})$ were marked, starting $1 \mathrm{~m}$ from the main edge (road or walking track) and running into the forest interior, along a north-south axis. Ten stations were located along the $150 \mathrm{~m}$ transects, $15 \mathrm{~m}$ apart. At each station, three microhabitats were examined; under the litter, on top of litter, and on vegetation at the "shrub layer" approximately $2 \mathrm{~m}$ off the ground (but connected to the canopy). Within each microhabitat, three types of baits were used: cotton wool soaked in a saturated sucrose solution ("sugar" bait), cotton wool soaked in soy cooking oil ("oil" bait), and tuna (chunky-style tuna in spring water [Sealord]) ("tuna" bait). Each cotton wool ball was approximately $5 \mathrm{ml}$ in volume, with an exposed surface area of $4-7 \mathrm{~cm}^{2}$. Approximately $2 \mathrm{~g}$ of tuna was used in each vial. Fresh baits were placed into a $25 \mathrm{ml}$ plastic vial $(25 \mathrm{~mm}$ diameter). For the shrub microhabitat, the vial was tied with wire to vegetation approximately $2 \mathrm{~m}$ off the ground. The baits within each microhabitat were placed in a triangular array, equidistant from each other with $30 \mathrm{~cm}$ spacing, and between microhabitats (within a station) there was at least $1 \mathrm{~m}$ spacing. After 1 $\mathrm{hr}$, vials were collected, capped, and taken to the laboratory. Vials were frozen to kill ants, and then ants were removed from the bait and placed into $75 \%$ ethanol. Each transect was completed on a separate day $(23,30 \mathrm{Sep}-$ tember, 1-3 October 2005), between 1000 and 1600 hours. Sampling was not undertaken when rain had fallen in the previous 6 hr. This gave 90 vials per transect and 450 vials overall.

\section{Specimen Identification}

There is no single publication to identify the ant species of Fiji, and knowledge of the ant fauna of Fiji is limited (Ward and Wetterer 2006). Shattuck and Barnett (2001) was used for identification to genus, and species-level identification was completed by examining reference specimens in the New Zealand Arthropod Collection (NZAC) and by using the publications of Mann (1921), and Wilson and Taylor (1967). The convention of Wetterer (2002) and Wetterer and Vargo (2003) was followed to define species as: endemic, which occur on the islands of Fiji and nowhere else; wide-ranging natives, which occur naturally in the Pacific island region; and invasive, which have been accidentally introduced to Fiji through human activities.

\section{Statistical Analyses}

The percentage similarity between litter and arboreal samples was calculated by the Sorensen's Quotient of Similarity $(\mathrm{Q} / \mathrm{S}) . \mathrm{Q} / \mathrm{S}=$ $[2 j /(a+b)] * 100$, where $a$ is the total number of species in sample $1, b$ is the number of species in sample 2 , and $j$ is the number of species common to both samples. Rarefaction (Coleman) curves were plotted of observed species richness, and the estimated number of ant species was calculated using the Chao 2 estimator of species richness using EstimateS v7.5 software (Colwell 2005). The efficiency of litter sampling was evaluated using the number of observed species divided by the Chao 2 estimate of species richness and is intended to be a measure of efficiency for this specific sampling method. The Shannon Diversity index $\left(H^{\prime}\right)$ and Simpson's index of evenness $(D)$ were also calculated using EstimateS. Differences in the ant species composition between the different tree categories from arboreal sampling (epiphytes, tree ferns, native species, mahogany, palm) were deter- 
mined by nonmetric multidimensional scaling in PRIMER v5.0 software (Clarke and Gorley 2001) using a Bray-Curtis similarity matrix on presence-absence data. Pairwise tests between the different tree categories were examined using Analysis of Similarities (ANOSIM). ANOSIM gives an $R$ value, which is a measure of the separation of pairwise comparisons on a scale from -1 to 1 : well separated, $>0.75$; clearly different, $>0.5$; and barely separable, $<0.25$ (Clarke and Gorley 2001).

Head width was used as an index of body size, a widely used measure of size in ants (Hölldobler and Wilson 1990). Measurements were made of mounted specimens, using an ocular micrometer calibrated with a stage micrometer to an accuracy of 0.033 $\mathrm{mm}$. Specimens were obtained from the sampling mentioned earlier. Measurements were made on 10 specimens of each species where possible. Only the minor castes of polymorphic taxa were used (e.g., Pheidole, Camponotus). Wilcoxon paired-sign tests were used to compare the differences in average body size of invasive and endemic species from each sample.

A two-factor analysis of variance (ANOVA) was used to examine the abundance of ants from the three microhabitats and three baits using SPSS v12.0.2 software (SPSS Inc., Chicago, Illinois). Stations were replicates. Transects were used as a covariate with Bonferroni post hoc tests. Differences in the composition of ant species from different microhabitat and food resources were determined by nonmetric multidimensional scaling in PRIMER, using a Bray-Curtis similarity matrix on presence-absence data from 10 runs (Clarke and Gorley 2001). Pairwise tests between microhabitats and food types were examined using ANOSIM.

\section{RESULTS}

\section{Diversity}

A total of 2,421 ants was collected from Colo-i-suva park, representing 27 species. Nine species were endemic to Fiji, 13 were native, and five species were invasive (Table
1). Nineteen species were caught in the arboreal samples, and 15 species from the litter. Sorensen's Quotient of Similarity $(\mathrm{Q} / \mathrm{S})$ between litter and arboreal samples was $52.9 \%$, with nine species common to both the arboreal and litter habitats (Table 1). Arboreal samples were dominated by species of Tetramorium, Camponotus, and Technomyrmex, whereas litter samples were dominated by species of Pheidole, Odontomachus, Hypoponera, and Solenopsis. Only two species, Paratrechina minutula and $P$. vaga, were frequently in both habitats. Ants were present in $93 \%$ $(n=57)$ of the litter quadrats but in only $65 \%(n=217)$ of arboreal samples. In the baiting experiment, ants were collected from only $51 \%$ of baited vials $(n=450)$.

Sampling was highly efficient, with the observed number of species being close to the Chao 2 estimated number of species for both arboreal (85.1\%) and litter (77.8\%). Shannon's $\left(H^{\prime}\right)$ and Simpson's $(1 / D)$ diversity indices indicated that arboreal samples had a higher diversity and evenness of species $\left(H^{\prime}=2.19, D=6.74\right)$ than litter quadrats $\left(H^{\prime}=1.98, D=5.26\right)$. The type of tree sampled did not affect the composition of ant species for arboreal samples. Pairwise comparisons showed that the ant composition of host tree categories was extremely similar to each other (ANOSIM $R<0.25$, stress = $0.09)$.

There was no difference in the number of invasive species caught from arboreal or litter samples $\left(2 \times 2\right.$ contingency table, $X^{2}=$ $0.147, P=.351)$. Paratrechina vaga, an invasive species, was the most common species in the litter and the third most common from arboreal samples. Paratrechina vaga was caught twice as frequently in the litter. This trend was repeated in the baiting experiment, where $P$. vaga was also caught twice as frequently in the litter (both top and under) compared with the shrub microhabitat. All other invasive species were seldom collected.

\section{Body Size}

Although the arboreal ant fauna had a larger head width (mean $\pm \mathrm{SE}=0.74 \pm 0.10 \mathrm{~mm}$ ), it was not significantly different (Wilcoxon 


\section{TABLE 1}

Frequency of Occurrence of Species Collected from Colo-i-suva Forest Park for Arboreal (Beating) and Litter (Quadrats) Samples, and the Three Microhabitat Layers from the Baiting Experiment (Shrub, Top of the Litter, and under the Litter).

\begin{tabular}{|c|c|c|c|c|c|}
\hline \multirow[b]{2}{*}{ Species } & \multirow[b]{2}{*}{ Arboreal } & \multirow[b]{2}{*}{ Litter } & \multicolumn{3}{|c|}{ Baiting Experiment } \\
\hline & & & Shrub & Litter: top & Litter: under \\
\hline \multicolumn{6}{|l|}{ Endemic } \\
\hline Camponotus dentatus (Mayr) & 0.029 & & & & \\
\hline Camponotus laminatus Mayr & 0.057 & & 0.188 & & \\
\hline Camponotus maudella Mann & 0.021 & & & & \\
\hline Camponotus manni umbratilis Mann & 0.043 & & & & \\
\hline Camponotus schmeltzi Mayr & 0.050 & & 0.031 & & \\
\hline Cerapachys cryptus Mann & & 0.019 & & & \\
\hline Hypoponera eutrepta (Wilson) & & 0.151 & & & \\
\hline Pheidole caldwelli Mann & 0.014 & 0.491 & 0.094 & 0.217 & 0.248 \\
\hline Pheidole wilsoni Mann & 0.007 & & & & \\
\hline \multicolumn{6}{|l|}{ Wide-ranging native } \\
\hline Odontomachus simillimus Smith & 0.007 & 0.226 & & 0.022 & \\
\hline Oligomyrmex atomus Emery & & & & 0.011 & 0.019 \\
\hline Paratrechina minutula (Forel) & 0.286 & 0.264 & 0.031 & & 0.010 \\
\hline Pheidole oceanica Mayr & 0.007 & & 0.031 & 0.011 & 0.038 \\
\hline Pheidole umbonata Mayr & & 0.038 & 0.031 & 0.033 & 0.010 \\
\hline Rogeria sublevinodis Emery & & & & & 0.010 \\
\hline Solenopsis papuana Emery & & 0.075 & 0.063 & 0.043 & 0.171 \\
\hline Strumigenys godeffroyi Emery & & 0.019 & & & \\
\hline Tapinoma minutum Emery & 0.093 & & & & \\
\hline Technomyrmex albipes (F. Smith) & 0.143 & 0.038 & & & \\
\hline Tetramorium insolens (F. Smith) & 0.064 & 0.019 & 0.063 & 0.011 & \\
\hline Tetramorium pacificum Mayr & 0.486 & 0.057 & 0.375 & & \\
\hline Vollenhovia denticulata Emery & 0.007 & & & & \\
\hline \multicolumn{6}{|l|}{ Invasive } \\
\hline Anoplolepis gracilipes (F. Smith) & 0.014 & 0.019 & & & \\
\hline Monomorium sechellense Emery & & 0.038 & & & \\
\hline Paratrechina vaga (Forel) & 0.250 & 0.585 & 0.125 & 0.283 & 0.276 \\
\hline Pheidole fervens Smith & 0.007 & & 0.031 & 0.011 & 0.048 \\
\hline Tapinoma melanocephalum (Fab.) & 0.043 & 0.019 & & & \\
\hline Total number of ants & 519 & 188 & 124 & 649 & 941 \\
\hline Number of species & 19 & 15 & 11 & 9 & 9 \\
\hline Number of samples & 140 & 53 & 32 & 92 & 105 \\
\hline
\end{tabular}

Note: Species are listed in alphabetical order within the categories of endemic, native, and invasive.

two-sample test, $W=40, P=.169)$ than in the litter $(0.48 \pm 0.05 \mathrm{~mm})$. In arboreal samples, the head width of invasive species was significantly smaller $(0.52 \pm 0.01 \mathrm{~mm})$ than that of endemic species $(1.17 \pm 0.06 \mathrm{~mm})$ (Wilcoxon paired test, $N=10, P<.001$ ). However, in the litter, there was no significant difference in head width between invasive $(0.51 \pm 0.01 \mathrm{~mm})$ and endemic species $(0.47 \pm 0.01 \mathrm{~mm})$ (Wilcoxon paired test, $N=\overline{12}, P=.134)$.
Abundance and Species Composition at Baits

Abundance data were skewed, but logtransformed data were normally distributed (one-sample Kolmogorov-Smirnov $Z=$ $0.921, P=.365)$. There was a significant difference in the abundance of ants between microhabitats (two-factor ANOVA, $F=26.53$; $\mathrm{df}=2,31 ; P<.001$ [Figure 2]), but abundance was not significantly different between bait type $(F=1.16 ; \quad \mathrm{df}=2,31 ; \quad P=.323)$. 


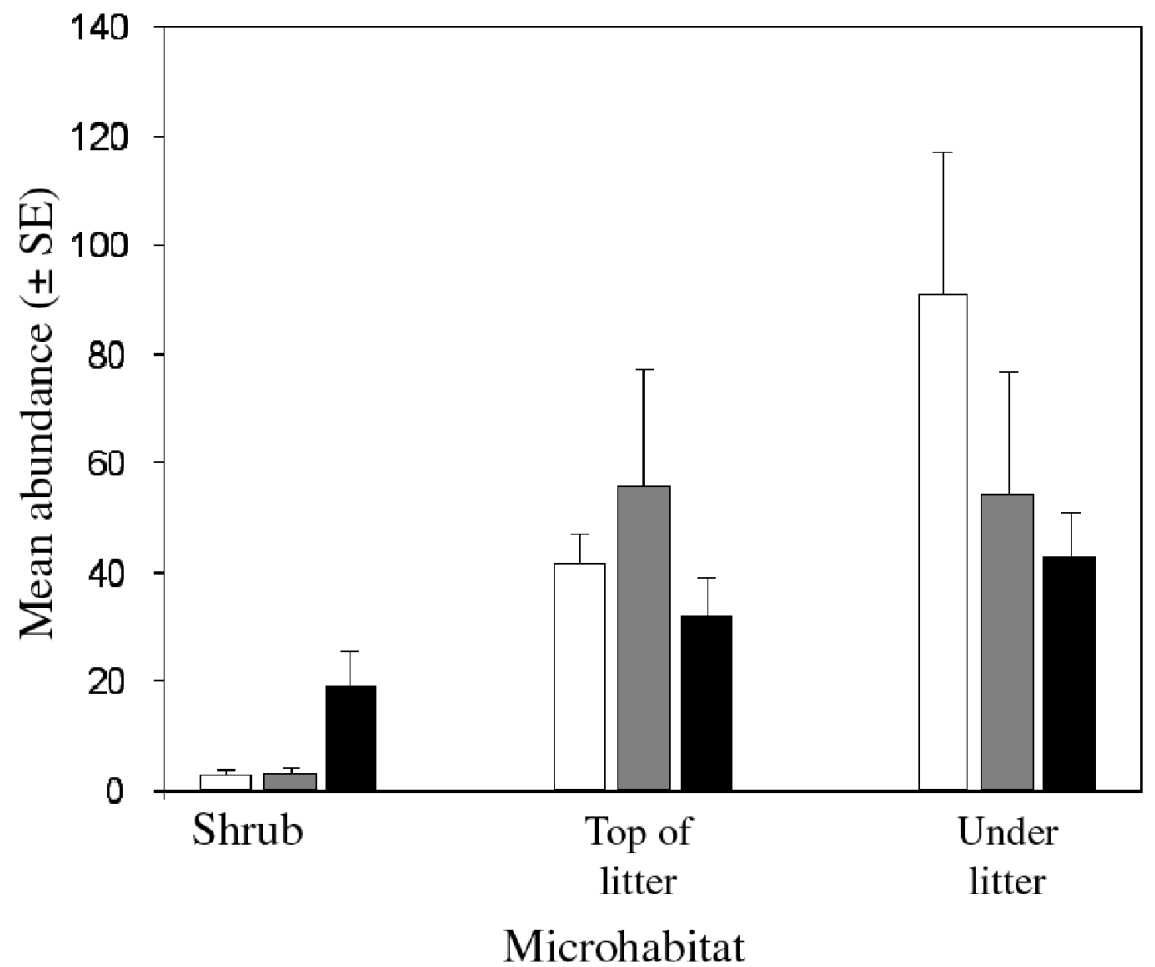

FIGURE 2. The mean abundance and standard error of ants from baited vials of oil (white), sugar (gray), and tuna (black), for the three microhabitat layers (shrub, on top of litter, under litter).

Bonferroni post hoc tests showed that both litter microhabitats had significantly more ants than shrub $(P<.05)$. There was no effect of transect as a covariate $(F=0.005$; $\mathrm{df}=4,31 ; P=.942)$. However, there was some evidence for an interaction between microhabitat and bait $(F=2.45 ; \mathrm{df}=4,31$; $P=.065$ ), with a higher abundance of ants collected from tuna on shrub. The abundance of the most common invasive species, $P$. vaga, was significantly lower in the shrub microhabitat than either on the top of or under the litter $(F=10.76$; df $=2,31 ; P<.001)$. The composition of ant species was significantly different between the shrub and both litter layers (shrub: top of litter, ANOSIM $R=$ $0.46, P<.001$; shrub: under litter, $R=0.53$, $P<.001$; stress $=0.08)$. However, the composition of ant species from the top of the litter was very similar to that from under the litter (under litter-top of litter, $R=0.11$, $P<.083)$. The composition of ant species at the three bait types was indistinguishable from one another (all combinations, ANOSIM $R<0.10, P>.30)$.

\section{DISCUSSION}

Arboreal and litter habitats often have distinct ant communities, the result of differences in resources and physical complexity (Yanoviak and Kaspari 2000). At Colo-i-suva Forest Park, spatial partitioning was evident between the arboreal and litter habitats with a relatively low species overlap. Arboreal samples also had a higher diversity of ant species compared with the litter and a different composition of ant genera. There was no evidence that ant assemblages were partitioned on the basis of floral associations. Each tree category 
(e.g., mahogany, palms, tree ferns, native tree species, and epiphytes) had a similar ant species composition.

The importance of spatial partitioning was further supported with the baiting experiment, which showed a strong difference in the abundance and composition of ant species between the shrub and litter layers. However, bait type was not partitioned by species, despite food being advocated as a major resource axis (Schoener 1974). Overall, there were no significant differences in the abundance of ants between the bait types, although there was a higher abundance $(P=$ .065 ) of ants on tuna baits from the shrub layer. Yanoviak and Kaspari (2000) have previously shown that the abundance of canopy ant species was higher on protein (tuna) baits compared with carbohydrate (sugar) baits and suggested that this was the result of greater nitrogen limitation in the canopy.

Susceptibility to invasion is related to the niche opportunities provided by different environments (Shea and Chesson 2002). Arboreal habitats are predicted to have not only a greater diversity of ant species but species with greater specialization, resource utilization, and behavioral aggression (Yanoviak and Kaspari 2000). As a consequence, the arboreal environment should provide more biotic resistance and thus be a more difficult environment to exploit for invasive ant species. At Colo-i-suva Forest Park, there was no difference in the total number of invasive ant species present between arboreal or the litter habitats, suggesting that there was no difference in the susceptibility from invasion between the two habitats. However, the most common invasive species, $P$. vag $a$, was significantly less abundant, and less frequently collected, in arboreal samples compared with the litter. These results could imply that $P$. vaga has a natural preference for ground habitats; however, they could also be interpreted as an inability to exploit the arboreal habitat because of biotic resistance.

Invasive ants may be able to exploit different niche opportunities that allow them to become established in arboreal habitats. However, this may require a combination of species-specific attributes and environmental circumstances (e.g., Heger and Trepl 2003). For example, in this study invasive species were significantly smaller than endemic species in arboreal samples but not in litter samples. The body size of invasive species did not change between the arboreal samples and litter, but rather the endemic ant fauna in the arboreal samples was larger. Environmental conditions in arboreal habitats are thought to favor larger worker size because of desiccation stress (Yanoviak and Kaspari 2000). Having a naturally larger-bodied ant fauna in the arboreal samples could have provided an opportunity for small invasive ant species to reduce/avoid interspecific competition with native species and become established. A larger-bodied ant fauna in Fiji could be the result of taxonomic disharmony, where Camponotus species dominate, and where many ant genera that are common and diverse elsewhere are absent.

Invasive ants represent a serious threat to biodiversity in Fiji and the Pacific region, and solutions to mitigate their impacts are urgently required. A greater understanding of the susceptibility of different habitats and whether invasive ants use different mechanisms to invade different habitats is needed.

\section{ACKNOWLEDGMENTS}

Thanks to staff at the Koronivia research station and the Colo-i-suva park headquarters for logistical support and their enthusiasm for the project. Also thanks to Eli Sarnat for taxonomic input, and Margaret Stanley and Jacqueline Beggs for comments on an early version of the manuscript.

\section{Literature Cited}

Albrecht, M., and N. Gotelli. 2001. Spatial and temporal niche partitioning in grassland ants. Oecologia (Berl.) 126:134-141.

Andersen, A. N. 1986. Patterns of ant community organization in mesic southeastern Australia. Aust. J. Ecol. 11:87-97.

. 1992. Regulation of momentary di- 
versity by dominant species in exceptionally rich ant communities of the Australian seasonal tropics. Am. Nat. 140:401-420.

Ash, J. 1987. Demography of Cyathea hornei (Cyatheaceae), a tropical tree-fern in Fiji. Aust. J. Bot. 35:331-342.

Clarke, K. R., and R. N. Gorley. 2001. PRIMER v5: User manual/tutorial. PRIMER-E, Plymouth, United Kingdom.

Colwell, R. K. 2005. EstimateS: Statistical estimation of species richness and shared species from samples. Version 7.5 (http:// purl.oclc.org/estimates).

Davidson, D. W. 1998. Resource discovery versus resource domination in ants: $\mathrm{A}$ functional mechanism for breaking the trade-off. Ecol. Entomol. 23:484-490.

Drake, J. A., H. A. Mooney, F. di Castri, R. H. Groves, F. J. Kruger, M. Rejmanek, and M. Williamson, eds. 1989. Biological invasions: A global perspective. John Wiley and Sons, New York.

Evenhuis, N. L., and D. J. Bickel. 2005. The NSF-Fiji terrestrial arthropod survey: Overview. Fiji Arthropod Series 1. Bishop Mus. Occas. Pap. 82:3-25.

Gotelli, N. J., and A. M. Ellison. 2002. Assembly rules for New England and assemblages. Oikos 99:591-599.

Heger, T., and L. Trepl. 2003. Predicting biological invasions. Biol. Invas. 5:313-321.

Hölldobler, B., and E. O. Wilson. 1990. The ants. Harvard University Press, Cambridge.

Holway, D. A. 1999. Competitive mechanisms underlying the displacement of native ants by the invasive Argentine ant. Ecology 80:238-251.

Holway, D. A., L. Lach, A. V. Suarez, N. D. Tsutsui, and T. J. Case. 2002. The causes and consequences of ant invasions. Annu. Rev. Ecol. Syst. 33:181-233.

Le Breton, J., H. Jourdan, J. Chazeau, J. Orivel, and A. Dejean. 2005. Niche opportunity and ant invasion: The case of Wasmannia auropunctata in a New Caledonian rain forest. J. Trop. Ecol. 21:93-98.

Lester, P. J., and A. Tavite. 2004. Longlegged ants, Anoplolepis gracilipes (Hymenoptera: Formicidae), have invaded Toke- lau, changing composition and dynamics of ant and invertebrate communities. Pac. Sci. 58:391-401.

Mann, W. M. 1921. The ants of the Fiji Islands. Bull. Mus. Comp. Zool. 64:401499.

McGlynn, T. P. 1999. The worldwide transfer of ants: Geographical distribution and ecological invasions. J. Biogeogr. 26:535548.

Morrison, L. W. 1996. Community organization in a recently assembled fauna: The case of Polynesian ants. Oecologia (Berl.) 107:243-256.

O'Dowd, D. J., P. T. Green, and P. S. Lake. 2003. Invasional 'meltdown' on an oceanic island. Ecol. Lett. 6:812-817.

Sanders, N. J., N. J. Gotelli, N. E. Heller, and D. M. Gordon. 2003. Community disassembly by an invasive ant species. Proc. Natl. Acad. Sci. U.S.A. 100:2474-2477.

Sarty, M., K. L. Abbott, and P. J. Lester. 2006. Habitat complexity facilitates coexistence in a tropical ant community. Oecologia (Berl.) 149:465-473.

Savolainen, R., and K. Vepsäläinen. 1989. Niche differentiation of ant species within territories of the wood ant Formica polyctena. Oikos 56:3-16.

Schoener, T. W. 1974. Resource partitioning in ecological communities. Science (Washington, D.C.) 185:27-39.

Shattuck, S. O., and N. J. Barnett. 2001. Australian ants online. (http://www.ento.csiro .au/science/ants/default.htm).

Shea, K., and P. Chesson. 2002. Community ecology theory as a framework for biological invasions. Trends Ecol. Evol. 17:170176.

Smith, A. C. 1979. Flora Vitiensis nova: A new flora of Fiji. Vol. 1. Pacific Tropical Botanical Garden, Hawai'i.

Ward, D. F., and J. K. Wetterer. 2006. Checklist of the ants of Fiji (Hymenoptera: Formicidae). Pages 23-47 in N. L. Evenhuis and D. J. Bickel, eds. Fiji Arthropod Series III. Bishop Mus. Occas. Pap. 85.

Watling, D. 2005. Palms of the Fiji Islands. Environmental Consultants, Suva. 
Wetterer, J. K. 2002. Ants of Tonga. Pac. Wilson, E. O., and R. W. Taylor. 1967. The

Sci. 56:125-135.
. 2006. Ants (Hymenoptera: Formicidae) of Niue, Polynesia. Pac. Sci. 60:413416.

Wetterer, J. K., and D. L. Vargo. 2003. Ants (Hymenoptera: Formicidae) of Samoa. Pac. Sci. 57:409-419. ants of Polynesia (Hymenoptera: Formicidae). Pac. Insects Monogr. 14:1-109.

Yanoviak, S. P., and M. Kaspari. 2000. Community structure and the habitat templet: Ants in the tropical forest canopy and litter. Oikos 89:259-266. 